\title{
A identificação da Função Logarítmica num trabalho com o software GeoGebra e futuros professores de Matemática
}

\section{Identifying the Logarithmic Function in a work with GeoGebra software and future Mathematic teachers}

\author{
Luciano Ferreira ${ }^{1}$ \\ Mariana Moran ${ }^{2}$ \\ Valdeni Soliani Franco ${ }^{3}$
}

\begin{abstract}
Resumo: Este artigo propõe uma sequência didática para o ensino da Função Logarítmica utilizando o software GeoGebra. A investigação foi realizada com alunos do $4^{\circ}$ ano de Licenciatura em Matemática de uma Universidade pública do norte do Paraná - Brasil. Aplicamos a sequência com o uso do software GeoGebra de modo que os alunos construíssem gradativamente o conceito de Função Logarítmica e suas propriedades. Utilizamos a definição dessa função, baseada no livro "Logaritmos" de Elon Lages Lima e investigamos se houve, pelos alunos, uma identificação da Função Logarítmica quando esta é definida de um modo menos usual. Concluímos que o objetivo da sequência didática foi alcançado, já que a maioria (9 de 12 alunos) conseguiu reconhecer a função logarítmica compreendendo sua interpretação geométrica. Mesmo com algumas respostas incompletas ou equivocadas durante a aplicação das tarefas, observamos que os alunos avançavam e refinavam as suas ideias e consequentemente as suas respostas.
\end{abstract}

Palavras chave: Sequência didática. Função Logarítmica. Investigação.

Abstract: This paper proposes a didactic sequence for teaching the Logarithmic Function using GeoGebra software. The research was conducted with students of the 4th year of Mathematics Degree at a public University of northern Paraná - Brazil. We applied the sequence using GeoGebra software so that students gradually built the concept of Logarithmic Function and its properties. We use the definition of this function based on the book "Logarithms" by Elon Lages Lima and investigate whether students have identified the Logarithmic Function when it is less commonly defined. We concluded that the objective of the didactic sequence was achieved, since most ( 9 of 12 students) were able to recognize the logarithmic function by understanding its geometric interpretation. Even with some

\footnotetext{
1 Doutor em Educação Matemática pela Universidade Estadual de Maringá - UEM; e-mail: lulindao66@hotmail.com

2 Doutora em Educação Matemática pela Universidade Estadual de Maringá - UEM; e-mail: mmbarroso@uem.br

${ }^{3}$ Pós-doutor em Educação Matemática pela Universidade de Évora - Portugal; e-mail: vsfranco@uem.br Tangram - Revista de Educação Matemática, Dourados - MS - v.2 n. 3, pp. 49-67 (2019)
} 


\section{A identificação da Função Logarítmica num trabalho com o software GeoGebra e futuros professores de Matemática}

incomplete or misleading answers while performing the tasks, we observed that students advanced and refined their ideas and consequently their answers.

Keywords: Didactic sequence. Logarithmic Function. Investigation.

\section{Introdução}

O presente estudo visa apresentar uma pesquisa realizada acerca do conteúdo Função Logarítmica, bem como uma das suas formas de apresentação e interpretação. O tema "Função Logarítmica" está presente no Ensino Médio no Brasil, e no Paraná ele está presente nas Diretrizes Curriculares da Educação Básica - DCE (Paraná, 2008), e é um conteúdo básico que faz parte do conteúdo estruturante Funções. Conforme as DCE:

As Funções devem ser vistas como construção histórica e dinâmica, capaz de provocar mobilidade às explorações matemáticas, por conta da variabilidade e da possibilidade de análise do seu objeto de estudo e por sua atuação em outros conteúdos específicos da Matemática (PARANÁ, 2008, p. 59).

É verificável na maioria dos livros didáticos do Ensino Médio brasileiro, que a Função Logarítmica é definida simplesmente, como a função inversa da Função Exponencial, ou como uma ferramenta para a resolução de Equações Exponenciais, ou ainda, a Função Logarítmica pode ser introduzida como um modo de exprimir os números na forma de potência de base dez.

Com base nessa abordagem para a Função Logarítmica comumente encontrada, despertou-nos a curiosidade sobre o modo pelo qual, alunos do Ensino Superior, mais especificamente, alunos do $4^{\circ}$ ano do curso de Licenciatura em Matemática, que já estudaram Função Logarítmica durante o Ensino Médio e também as aplicaram para resolução de diversos problemas durante a graduação, concebem este conceito.

Para alcançar nossas intenções oferecemos uma oficina para 12 alunos em formação inicial do $4^{\circ}$ ano do curso de Licenciatura em Matemática em uma Universidade pública no interior do Paraná, onde foi elaborada e aplicada uma sequência didática composta por 7 tarefas. Mas, no âmbito desse artigo, nos reportaremos a essas tarefas dando uma ênfase maior para as três últimas.

Sendo assim, para trabalharmos o conceito de Função Logarítmica, utilizamos como livro base o Logaritmos de Elon Lages Lima (2010). Neste livro, o conceito de Logaritmo Natural é introduzido como a identificação da área de uma faixa de hipérbole e deste modo, Tangram - Revista de Educação Matemática, Dourados - MS - v.2 n. 3, pp. $49-67$ (2019) 


\section{A identificação da Função Logarítmica num trabalho com o software GeoGebra e futuros professores de Matemática}

todas as propriedades dos logaritmos podem ser verificadas. Ou seja, definimos o logaritmo neperiano $(\ln )$ por $\ln (t)=\int_{1}^{t} \frac{1}{x} d x$, admitindo o seguinte teorema: “Toda função f contínua em um intervalo I tem primitivas", então existe $F$ que é primitiva de $f$ tal que $F(1)=0$.

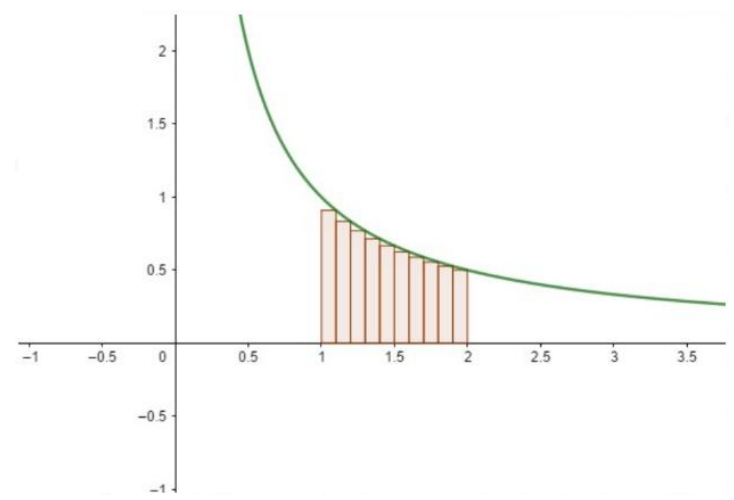

Figura 1- Hipérbole

Fonte: autores

De acordo com Lima (2010, p. 31), “a concepção geométrica de uma Função Logarítmica é uma ideia muito antiga, com mais de três séculos e meio de existência. Além de antiga, ela é natural, intuitiva e instrutiva". Deste modo, pensando em como podemos abordar tal assunto, Almouloud (2011) afirma que não devemos ensinar o conceito de Função Logarítmica por meio de integral no $3^{\circ}$ ano do Ensino Médio. No entanto, como trabalhamos esta abordagem com os alunos do Ensino Superior, pudemos utilizar integrais pelo fato destes já terem estudado conceitos relacionados à soma de Riemann, integral definida e, principalmente, a relação entre a integral definida e o logaritmo neperiano, ou melhor, $\ln (t)=\int_{1}^{t} \frac{1}{x} d x$. Ressaltamos que durante a oficina oferecida, exploramos mais os aspectos geométricos justamente pela suposição de que os aspectos algébricos surgiriam naturalmente em decorrência da abordagem geométrica, além da suposição de que tais aspectos já foram devidamente explorados durante suas graduações, incluindo as definições e propriedades convenientes etc.

Para que essa abordagem ficasse mais nítida e os objetivos da pesquisa fossem alcançados, convencionamos utilizar uma aula investigativa com o software dinâmico GeoGebra, pois deste modo os alunos poderiam explorar a construção e os cálculos das respectivas áreas abaixo da curva hiperbólica que foi proposta.

Tangram - Revista de Educação Matemática, Dourados - MS - v.2 n. 3, pp. $49-67$ (2019) 


\section{A identificação da Função Logarítmica num trabalho com o software GeoGebra e futuros professores de Matemática}

Portanto, o objetivo deste trabalho foi realizar operações no software GeoGebra de modo que gradativamente os alunos fossem conduzidos a realizar tarefas verificando seus resultados de modo a alcançar o conceito de Função Logarítmica e suas propriedades.

Então, o problema que norteou a pesquisa foi: ao submeter alunos do $4^{\circ}$ ano de licenciatura em Matemática (futuros professores) a uma sequência didática usando o software GeoGebra, estes serão capazes de construir o conceito de Função Logarítmica quando esta é definida geometricamente, ou seja, de modo diferente dos comumente utilizados pelos livros didáticos?

\section{A contribuição do GeoGebra nas aulas investigativas}

As mídias na educação tem sido um tema presente tanto na Educação Básica como no Ensino Superior. De acordo com Frota (2007, p. 8), "Um conjunto significativo de pesquisas sobre o uso das Tecnologias de Informação e Comunicação (TICs) no ensino de matemática tem sido conduzido no interior das universidades brasileiras".

Hoje, pelo menos no estado do Paraná, tem-se o programa Inovação Educação Conectada com o objetivo de apoiar a universalização do acesso à internet e de fomentar o seu uso pedagógico. Esse programa será desenvolvido até 2024 e busca suprir a necessidade de inovações e tecnologias em sala de aula (PARANÁ, 2019). Por isso, entendemos a necessidade de oportunizar tarefas que utilizem tecnologias num contexto educacional.

Este artigo apresenta uma proposta de uma sequência didática de introdução à Função Logarítmica que utiliza uma abordagem investigativa por meio do software GeoGebra. Esta sequência visa relacionar o modo como os logaritmos são ensinados no Ensino Médio e no Superior. A investigação realizada pelos participantes durante a oficina é subsidiada por um contexto de experiência matemática, ou seja, cria-se um ambiente de especulação, argumentação e da própria investigação com o objetivo de desenvolver uma atividade matemática. Frota (2007) explica que tanto para o professor quanto para o aluno, as questões de aprender e ensinar matemática fazem parte de uma experiência matemática.

Para Brousseau (1996) a aprendizagem ocorre conforme o aluno se adapta ao meio, ou seja, quando este se depara com dificuldades, contradições, impossibilidades etc., e precisa refletir e tomar decisões para evoluir e encontrar a solução da tarefa. Ponte et al (1998) defende que a investigação matemática na sala de aula é um modo de ensino que

Tangram - Revista de Educação Matemática, Dourados - MS - v.2 n. 3, pp. $49-67$ (2019) 


\section{A identificação da Função Logarítmica num trabalho com o software GeoGebra e futuros professores de Matemática}

possibilita o trabalho adequado a cada nível de capacidade e estimula a necessidade de justificativas para as afirmações realizadas.

Nesse sentido, ao pensar no uso do GeoGebra para uma investigação, vemos que este software, além de permitir, ele instiga seus usuários a explorar dados e formular questões, como também a realizar conjecturas com seus respectivos testes e justificativas. Tais ações são propícias àqueles que buscam realizar uma investigação matemática baseada em descobertas e desafios. Esses foram alguns dos motivos que nos conduziram na escolha por trabalhar com o GeoGebra.

O GeoGebra é um software livre de geometria dinâmica, composto por duas janelas: uma que exibe a área de desenho e outra que exibe objetos aritmético-algébricos. Vinculado a essa janela algébrica existe um campo de entrada, no qual podem ser digitados comandos analíticos para o traçado de objetos na área de desenho.

Podemos dizer que o GeoGebra além de ser um software gratuito de matemática dinâmica, ele permite trabalhar a Geometria, a Álgebra, o Cálculo e a Estatística. Este software nos oferece a oportunidade de visualizar a relação da representação algébrica com a geométrica de um objeto em estudo. Ele está instalado em todos os computadores das escolas estaduais do estado do Paraná, e pode ser instalado em qualquer computador sem custo, sendo que também está disponível para androides e ios dos smartphones.

Porém para Ferreira e Barros (2010), o uso de um software de geometria dinâmica pode, quando mal utilizado, colaborar para a formação de conceitos alternativos (não científicos), e por esse motivo, no momento da oficina, além de direcionarmos a construção da função no software, optamos por elaborar uma sequência didática que foi entregue aos participantes com o "passo a passo" de cada fragmento da construção. Nessa sequência contém informações técnicas de auxílio a construção e, também um direcionamento para a investigação a ser realizada pelo aluno, já que as atividades investigativas proporcionam a descoberta de informações matemáticas que poderiam ter sido simplesmente apresentadas pelo professor. "Ao iniciar a investigação, é importante que o aluno saiba o que lhe é pedido, em termos de produto final" (PONTE et al., 2006, p.29). Mesmo se tratando de uma aula investigativa, o aluno precisa ter uma motivação e curiosidade a ser sanada para que a investigação faça sentido.

Conforme Fiorentini e Lorenzato (2006, p. 46), as tecnologias de informação e comunicação (TICs) permitem aos estudantes estudar temas tradicionais de maneira nova.

Tangram - Revista de Educação Matemática, Dourados - MS - v.2 n. 3, pp. $49-67$ (2019) 


\section{A identificação da Função Logarítmica num trabalho com o software GeoGebra e futuros professores de Matemática}

Assim, a investigação aliada à tecnologia é uma ferramenta, que quando bem utilizada, é eficaz no processo de ensino e na formação de professores de Matemática.

No caso deste trabalho, achamos pertinente o uso da abordagem investigativa, pois toda a motivação teórica foi feita a partir de tarefas que foram propostas aos alunos e para respondê-las estes precisaram executar comandos no GeoGebra que corroboraram ou não com suas conjecturas. O uso do software GeoGebra aliado à investigação matemática desenvolveu competências nos alunos, como: aprender a manusear um software matemático; a possibilidade do uso de ferramentas computacionais nas aulas de Matemática; a aprendizagem de uma nova abordagem para o Cálculo; o reconhecimento da Função Logarítmica como uma Soma de Riemann; a investigação como uma possibilidade de aprendizagem; dentre outras.

Desta forma, com este curso, os acadêmicos participantes tiveram a oportunidade de entender esta relação desconhecida por eles mesmos, conforme veremos nos resultados desta pesquisa.

Com o intuito de responder a pergunta desta pesquisa, direcionamos nosso trabalho conforme relatado na seção seguinte.

\section{Metodologia e estratégias de ação}

Para atender ao objetivo principal, fundamentamos esta investigação na abordagem da pesquisa qualitativa no paradigma interpretativo, haja vista que o "qualitativo engloba a ideia do subjetivo, passível de expor sensações e opiniões” (Bicudo, 2004, p.104).

Os alunos, sujeitos dessa pesquisa, participaram de uma oficina oferecida pelos pesquisadores, autores deste artigo, que ocorreu no Laboratório de Informática do Departamento de Matemática da Universidade. A oficina teve a duração de 4 h/a com a participação de 12 alunos de Licenciatura em Matemática.

Para analisar e interpretar os dados usamos traços da análise de conteúdo, pois ela "enriquece a tentativa exploratória, aumenta a propensão à descoberta" (Bardin, 1977, p.30). Para organizar os dados coletados, utilizamos unidades de análise que foram estabelecidas pelos pesquisadores após uma leitura detalhada das tarefas respondidas pelos alunos e classificamos as atividades realizadas conforme dois aspectos: construção e reconhecimento, conforme o quadro a seguir:

Tangram - Revista de Educação Matemática, Dourados - MS - v.2 n. 3, pp. $49-67$ (2019) 


\section{A identificação da Função Logarítmica num trabalho com o software GeoGebra e futuros professores de Matemática}

Quadro 1 - Unidades de análise das atividades propostas

\begin{tabular}{|c|c|c|}
\hline \multicolumn{3}{|c|}{ Construção da função } \\
\hline Fase 1 & Não realizada ou inadequada & $\begin{array}{c}\text { Tarefa em branco ou inadequadamente } \\
\text { resolvida }\end{array}$ \\
\hline Fase 2 & Incompleta & Tarefa sem finalizar \\
\hline Fase 3 & Adequada & Tarefa realizada de acordo \\
\hline \multicolumn{3}{|c|}{$\underline{\text { Reconhecimento da função }}$} \\
\hline Fase 4 & Não realizado ou inadequado & $\begin{array}{c}\text { Tarefa em branco ou inadequadamente } \\
\text { resolvida }\end{array}$ \\
\hline Fase 5 & Incompleto & Tarefa sem finalizar \\
\hline Fase 6 & Adequado & Tarefa realizada de acordo \\
\hline
\end{tabular}

Fonte: autores

Neste quadro, separamos as unidades por Fases, no entanto, como estão subdivididas entre os aspectos "construção" e "reconhecimento", observamos que essas Fases não indicam, necessariamente, uma ascensão de conhecimento matemático por parte dos alunos que as compõem, conforme será visto na análise dos resultados.

Os resultados coletados foram corrigidos de acordo com a teoria matemática descrita na obra Logaritmos do pesquisador Elon Lages Lima, de modo a confrontar as resoluções realizadas pelos participantes.

Os dados para a análise foram coletados com o uso de questões matemáticas abertas que foram respondidas pelos alunos ao utilizarem o software GeoGebra como apoio. O GeoGebra foi decisivo para a construção da Função Logarítmica, pois este permitiu identificar com naturalidade os aspectos que pretendíamos estudar.

Foram propostas 7 (sete) tarefas de construção com o objetivo de fornecer subsídios de ferramentas para que os alunos pudessem construir a Função Logarítmica. Ao final de cada tarefa os alunos responderam questões de modo a reconhecer propriedades e conceitos da função a ser investigada. Principalmente, as três últimas tarefas, bem como as suas respectivas questões exploratórias, propiciaram dados para que o problema de pesquisa fosse respondido.

Tal abordagem para o conceito da Função Logarítmica não é comumente apresentada ou explorada com os alunos quando essa função é estudada, o que gerou certa dificuldade de reconhecimento e compreensão pelos participantes no momento da exploração. Tangram - Revista de Educação Matemática, Dourados - MS - v.2 n. 3, pp. $49-67$ (2019) 


\section{A identificação da Função Logarítmica num trabalho com o software GeoGebra e futuros professores de Matemática}

Almouloud (2011), explica que as dificuldades dos alunos em compreender o conceito que rege a Função Logarítmica se deve ao fato de que determinados conhecimentos científicos, dependendo do nível em que é trabalhado, precisa ser acessível aos alunos. As dificuldades na aprendizagem da Função Logarítmica são percebidas principalmente quando se refere à concepção e formação de conceitos.

Neste caso explanou-se as propriedades, o comportamento, o domínio e a imagem da Função Logarítmica sem que os sujeitos participantes soubessem à priori que essas características eram referentes à Função Logarítmica. Para trabalhar com o conceito destas funções, utilizamos uma abordagem geométrica com o apoio do GeoGebra.

No desenvolvimento desta pesquisa utilizamos, por meio da sequência didática, a investigação matemática, pois esta metodologia compatibiliza com o objetivo principal do trabalho. Ou seja, por meio da investigação matemática, os alunos, curiosamente, chegariam ou não, a conclusões referentes à noção de Função Logarítmica. Para Bertini e Passos (2008), as atividades investigativas exigem do professor conhecimento suficiente para que este promova o envolvimento do aluno em atividades que se refiram aos conceitos com os quais deseja trabalhar.

A oficina oferecida abordou assuntos introdutórios sobre o GeoGebra, bem como, algumas atividades iniciais para que os alunos conhecessem os principais comandos deste software. Em seguida, trabalharam-se conceitos referentes à Função Logarítmica sem especificar aos alunos participantes que se tratava deste conteúdo.

O curso foi distribuído do seguinte modo:

1 a parte: apresentação das noções básicas do software GeoGebra;

$\mathbf{2}^{\mathbf{a}}$ parte: realização de atividades que introduziram, implicitamente, conceitos e propriedades referentes à Função Logarítmica com o GeoGebra e investigação das competências dos alunos em reconhecê-la como tal.

$\mathbf{3}^{\mathbf{a}}$ parte: definição formal da Função Logarítmica.

\section{Resultados obtidos}

A análise dos resultados está organizada por Fases dentro dos aspectos "construção" e "reconhecimento" A intenção é refletir a partir da prática no que diz respeito ao uso de tecnologias em meio a uma abordagem exploratória, principalmente num ambiente de formação inicial de professores.

Tangram - Revista de Educação Matemática, Dourados - MS - v.2 n. 3, pp. $49-67$ (2019) 


\section{A identificação da Função Logarítmica num trabalho com o software GeoGebra e futuros professores de Matemática}

Um dos motivos que nos levou a realizar a presente pesquisa foi, será que conseguimos relacionar alguns conteúdos estudados no Ensino Médio ao Ensino Superior? Para isso fizemos a seguinte pergunta: ao submeter alunos do $4^{\circ}$ ano de licenciatura em Matemática a uma sequência didática usando o software GeoGebra, estes serão capazes de construir o conceito de Função Logarítmica quando esta é definida geometricamente, ou seja, de modo diferente dos comumente utilizados pelos livros didáticos?

Percebemos que durante a realização da parte experimental, poucas foram as manifestações de dificuldades ao trabalhar com um software dinâmico, já que a maioria dos alunos já conhecia o GeoGebra. Somente alguns participantes não conheciam as ferramentas básicas e tiveram problemas na execução dessas ferramentas. Alguns apresentaram dificuldade para digitar os caracteres para a construção da função e durante a exploração de seu gráfico, no entanto, as dificuldades foram diminuindo a medida que o trabalho no software era executado.

Para descrever a análise, identificamos cada participante por A1, A2, e assim por diante, até A12.

Antes da análise das tarefas 5 à 8 , apresentaremos as tarefas 1 à 4 que compõem aspectos da construção da função, conforme descrito a seguir:

\section{TAREFA 1:}

DEF: Seja $H$ o ramo positivo do gráfico da função $y=1 / x$, isto é, da função que associa a cada número real positivo $x$, o número $y=1 / x$.

Sendo assim a função $H$ é $H=\left\{(x, y) \mid x>0, y=\frac{1}{x}\right\}$.

Abra uma janela do GeoGebra, conforme a figura ao lado. Vamos construir a função $H$ utilizando o GeoGebra.

\section{Figura 2 - Tarefa 1}

Fonte: autores

O objetivo desta tarefa foi a construção do gráfico da hipérbole no primeiro quadrante, conforme a Figura 2, de modo que o comportamento das coordenadas $x$ e $y$ fosse analisado conforme as questões da Figura 3. 
A identificação da Função Logarítmica num trabalho com o software GeoGebra e futuros
professores de Matemática

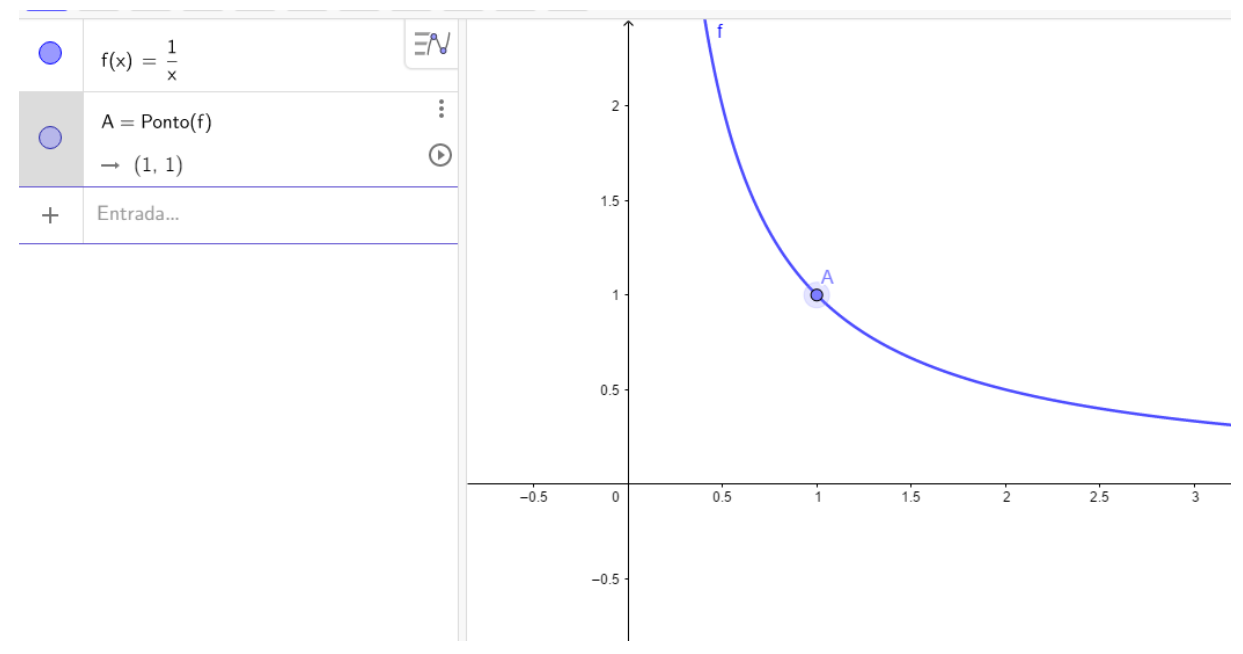

Figura 3 - Função $H$

Fonte: autores

1.1) Existe algum intervalo que a coordenada $y$ é maior que $x$ ? Se existe diga qual e porque isto acontece.

1.2) Existe algum intervalo que a coordenada $x$ é maior que $y$ ? Se existe diga qual e porque isto acontece.

1.3) Existe alguma relação entre as coordenadas $(x, y)$ ? Caso exista, descreva-a.

Figura 4 - Questões da Tarefa 1

Fonte: autores

Essas questões conduziriam o participante a visualizar o comportamento do gráfico da função $H$ de modo a investigar a relação entre as coordenadas $x$ e $y$.

A Tarefa 2 teve como objetivo calcular as Somas de Riemann inferiores de dois intervalos pré-determinados. Conforme a Figura 5:

\section{TAREFA 2:}

Abra uma nova janela do GeoGebra.

Pretendemos construir a seguinte função $H=\left\{(x, y) \mid x>0, y=\frac{1}{x}\right\}$. e calcular as somas inferiores de dois intervalos. Para isto, proceda do mesmo modo que construiu a referida função na Atividade 1 .

Logo após, utilizando outra vez o campo "entrada", calcule as somas inferiores de dois intervalos, conforme explicação a seguir.

\section{Figura 5 - Tarefa 2}

Fonte: autores

A seguir, na Figura 6, tem-se a janela de álgebra e a janela do gráfico referente a Tarefa 2:

Tangram - Revista de Educação Matemática, Dourados - MS - v.2 n. 3, pp. $49-67$ (2019) 


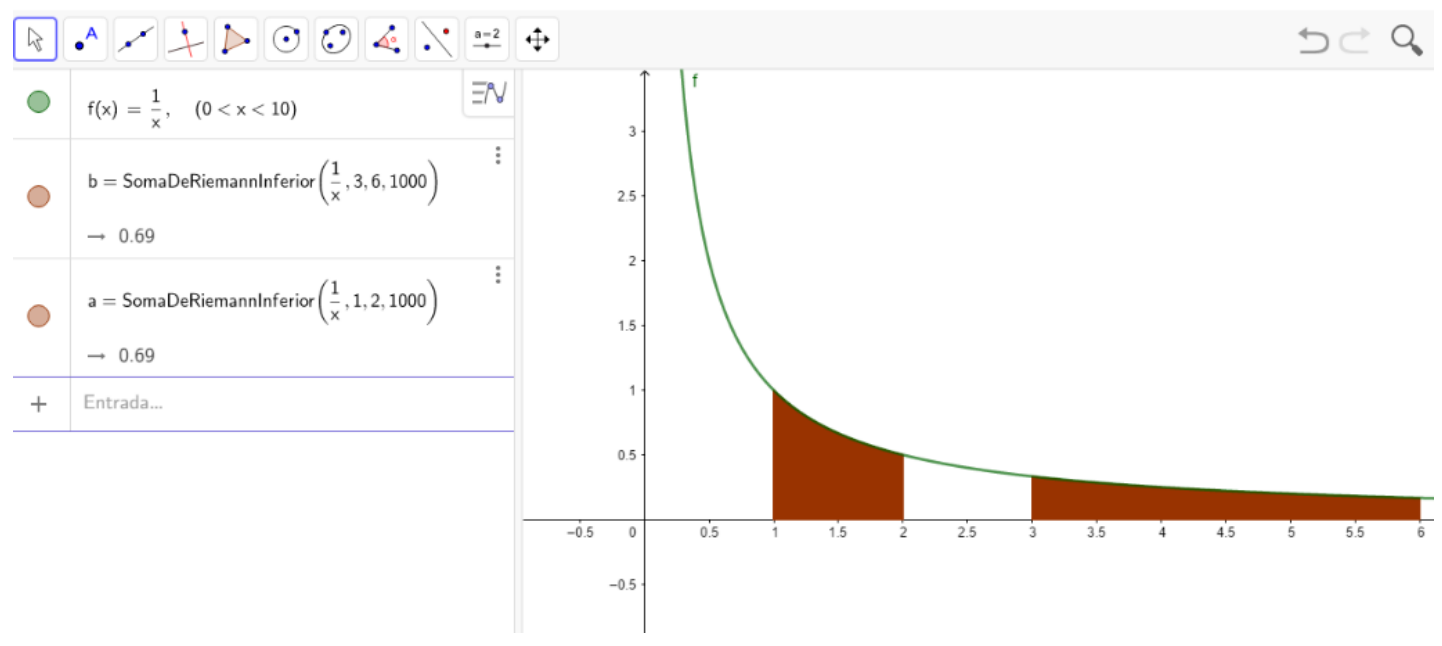

Figura 6 - Construção da Tarefa 2

Fonte: autores

Baseado nesta construção, os participantes deveriam responder as seguintes questões:

2.1) Qual a relação do valor de $\mathbf{a}$ com de $\mathbf{b}$ ?

2.2) Se você mudar em a os valores inicial e final para $1 \frac{1}{2}$ e 1 respectivamente o que acontece?

2.3) Olhando no gráfico, o que pode se afirmar dos retângulos traçados para calcular as somas inferiores?

Figura 7 - Questões da Tarefa 2

Fonte: autores

Ao responder essas questões, o participante observaria a mudança de comportamento dos retângulos inscritos a medida em que os valores inicial e final forem mudando.

Na Tarefa 3, o objetivo foi direcionar os alunos a investigar a área de uma determinada região limitada por $[a, b]$, conforme o número de retângulos que particiona a área tende a infinito.

\section{TAREFA 3:}

\section{Continue na janela da Atividade 2 do GeoGebra:}

Desejamos verificar se a área da região $H=\left\{(x, y) \mid x>0, y=\frac{1}{x}\right\}$. limitada por $[a, b]$ é na verdade o limite da soma de todos retângulos da divisão, em $n$ partes iguais, dos intervalos $[c, d]$ ou $[k c, k d]$, quando $n$ tende ao infinito.

Ou seja, em outras palavras, se na atividade anterior no campo entrada ao invés de ter digitado 10 no $\mathrm{n}^{\circ}$ de retângulos, digitarmos 1000, 10000, ou 100000 o que acontece? Tente trocar o 10 por 100 depois 1000,1000 e 10000 no campo entrada como na figura a seguir:

\section{Figura 8 - Tarefa 3}

Fonte: autores

Tangram - Revista de Educação Matemática, Dourados - MS - v.2 n. 3, pp. $49-67$ (2019) 


\section{A identificação da Função Logarítmica num trabalho com o software GeoGebra e futuros professores de Matemática}

As questões a seguir, direcionaram a investigação:

3.1) O que acontece quando vocês realizam as trocas?

3.2) Neste caso, qual seria o melhor valor para $n$ ?

Podemos convencionar que: para cada faixa $H_{a}^{b}$, vamos definir o número:

$$
L\left(H_{a}^{b}\right)= \begin{cases}- \text { Área } H_{a}^{b}, & \text { se } a>b \\ 0, & \text { se } a=b \\ \text { Área } H_{a}^{b}, & \text { se } b>a\end{cases}
$$

3.3) Você se lembra de ter estudado a função $L\left(H_{a}^{b}\right)$ conforme definida acima?

3.4) Você se lembra de ter estudado a função $f(x)=\frac{1}{x}$ ? Caso tenha a estudado, em quais situações?

3.5) De acordo com as atividades realizadas até o momento, você saberia descrever qual a relação entre as funções $L\left(H_{a}^{b}\right)$ e $f(x)=\frac{1}{x}$ ? Se sim, descreva.

3.6) Existe alguma função que satisfaz $L\left(H_{a}^{b}\right)$ ?

3.7) Pode se afirmar que dado intervalo [a,c], Área $H_{a}^{c}=$ Área $H_{a}^{b}+$ Área $H_{b}^{c}$ para um $b \in[a, c]$. Para responder esta questão, utilize o GeoGebra, dividindo um intervalo da função e calculando, parte por parte e depois todo o intervalo.

\section{Figura 9 - Questões da Tarefa 3}

Fonte: autores

Com essas questões, buscou-se direcionar o aluno a refletir a respeito do desconhecido se tornar conhecido. Ou seja, por meio da investigação geométrica, o aluno poderá reconhecer o comportamento da função L e assim justificar as propriedades da Função Logarítmica.

$\mathrm{Na}$ Atividade 4, define-se a função L(x) e, em seguida, as questões direcionam os alunos a estudar o comportamento em determinados pontos da abscissa $x$.

\section{TAREFA 4:}

DEF: Seja $x$ um número real positivo. Definiremos uma função $L(x)$ como a área da faixa $H_{1}^{x}$. Assim, por definição, quando $x>0$, Temos: $L(x)=$ Área $\left(H_{1}^{x}\right)$. Lembre-se que por convenção Área $\left(H_{1}^{x}\right)<0$ se $0<x<1$.

Agora utilizando o GeoGebra vamos calcular: $L(1), L(2)$ e $L(3)$.

4.1) O que se pode afirmar de $L(1)$ :

4.2) O que se pode afirma de $L(2)$ e $L(3)$ :

4.3) Existe algum valor de $x$ tal que $L(\mathrm{x})=1$ ?

Tangram - Revista de Educação Matemática, Dourados - MS - v.2 n. 3, pp. $49-67$ (2019) 
A identificação da Função Logarítmica num trabalho com o software GeoGebra e futuros professores de Matemática

4.2) O que se pode afirma de $L(2)$ e $L(3)$ :

4.3) Existe algum valor de $x$ que $L(\mathrm{x})=1$ ?

Figura 10 - Tarefa 4

Fonte: autores

O objetivo dessa tarefa é continuar testando mais algumas propriedades da Função Logaritmica sem que os alunos se dêem conta de tal fato.

No momento da Tarefa 5, a investigação permeou a verificação de uma das propriedades da Função Logaritmica. A princípio, tal estudo foi feito utilizando valores para $x$, no entanto, as questões relativas a essa atividade direcionaram os participantes à generalização do comportamento observado com a atividade.

Reconhecemos as Fases em que cada um dos alunos se encontra ao resolver tais atividades. Com base nas respostas coletadas, os 12 alunos se enquadraram na Fase 3, ou seja, todos fizeram a construção adequada do gráfico da função logarítmica no software GeoGebra e calcularam as somas inferiores dentro de intervalos conforme solicitado nas atividades, conforme Figura a seguir:

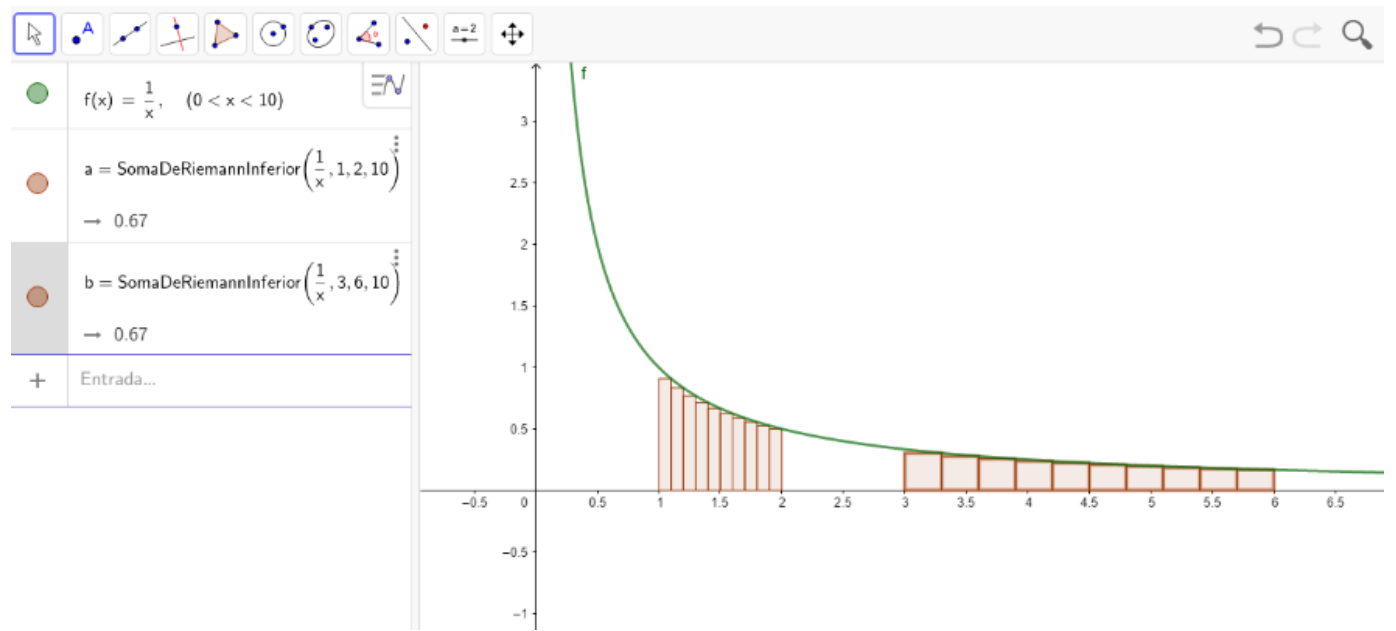

Figura 11 - Somas inferiores da Tarefa 5

Fonte: autores

Análise referente ao reconhecimento da função: a partir da Tarefa 5, iniciamos um trabalho de reconhecimento da Função Logarítmica em que os alunos eram direcionados pelas tarefas. Iniciamos com a propriedade que afirma que o $\log$ do produto é a soma dos log's. No entanto, tal propriedade foi investigada por meio das áreas dos retângulos construídos, conforme a Tarefa 5, a seguir:

\section{TAREFA 5:}

Nesta atividade, queremos mostrar algumas propriedades de $L(x)$ :

Tangram - Revista de Educação Matemática, Dourados - MS - v.2 n. 3, pp. $49-67$ (2019) 

professores de Matemática

Seja $L: \mathbb{R}^{+} \rightarrow \mathbb{R}$, queremos mostrar que $L(x . y)=L(x)+L(y)$.

Ora, já vimos que:

$$
\text { Área } H_{1}^{x y}=\text { Área } H_{1}^{x}+\text { Área } H_{x}^{x y}
$$

Agora usando o GeoGebra verifique se a igualdade acima é verdadeira, para isto calcule, por exemplo: $H_{1}^{6}$ depois calcule $H_{1}^{2}$ e $H_{2}^{6}$ sendo assim $x=2$ e $y=3$.

Feito isto responda:

5.1) É possível verificar se Área $\left(H_{1}^{x y}\right)=$ Área $\left(H_{1}^{X}\right)+$ Área $\left(H_{x}^{x y}\right)$ ? Se possível explique como fazer isto usando o GeoGebra:

5.2) Usando a verificações acima, diga por que podemos afirmar que $L(x . y)=L(x)+L(y)$ :

Figura 12 - Tarefa 5

Fonte: autores

Com relação à questão 5.1, 8 alunos responderam que é possível verificar a propriedade, mas somente 5 destes justificaram respondendo ao item 5.2. Conforme a resposta a seguir:

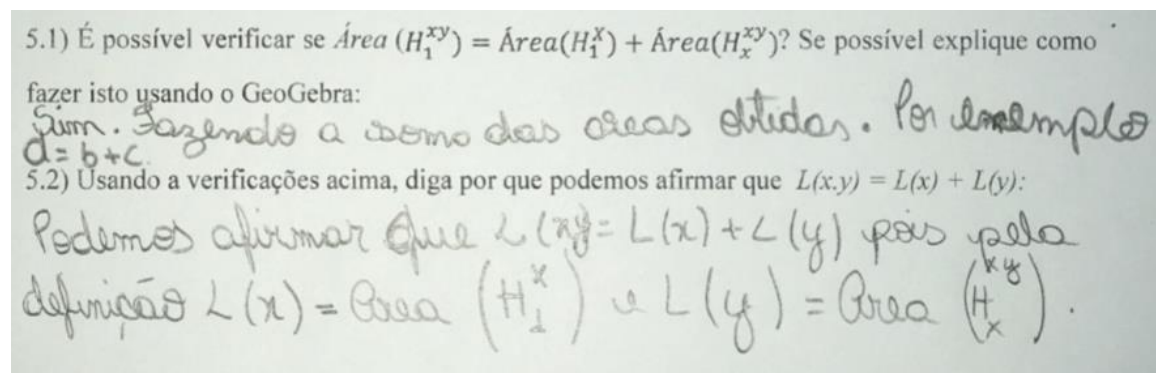

Figura 13 - Registro de A1

Fonte: autores

Dos 12 alunos, 4 responderam não saber como verificar tal igualdade, e nenhum aluno respondeu não ser possível.

Então, na Tarefa 6, outras propriedades da Função Logarítmica foram estudadas por meio do GeoGebra.

TAREFA 6:

Utilizando o GeoGebra faça a verificação das seguintes propriedades:

$L(x / y)=L(x)-L(y)$ e $L\left(x^{m}\right)=m L(x)$.

6.1) Escreva passo a passo o que fez no GeoGebra para verificar estas propriedades.

\section{Figura 14 - Tarefa 6}

Fonte: autores

Os alunos A1, A2, A4, A7, A8, A9, A10, A11 e A12 mostraram o passo a passo da Tangram - Revista de Educação Matemática, Dourados - MS - v.2 n. 3, pp. $49-67$ (2019) 


\section{A identificação da Função Logarítmica num trabalho com o software GeoGebra e futuros professores de Matemática}

verificação dessas propriedades no GeoGebra, conforme registro de A9:

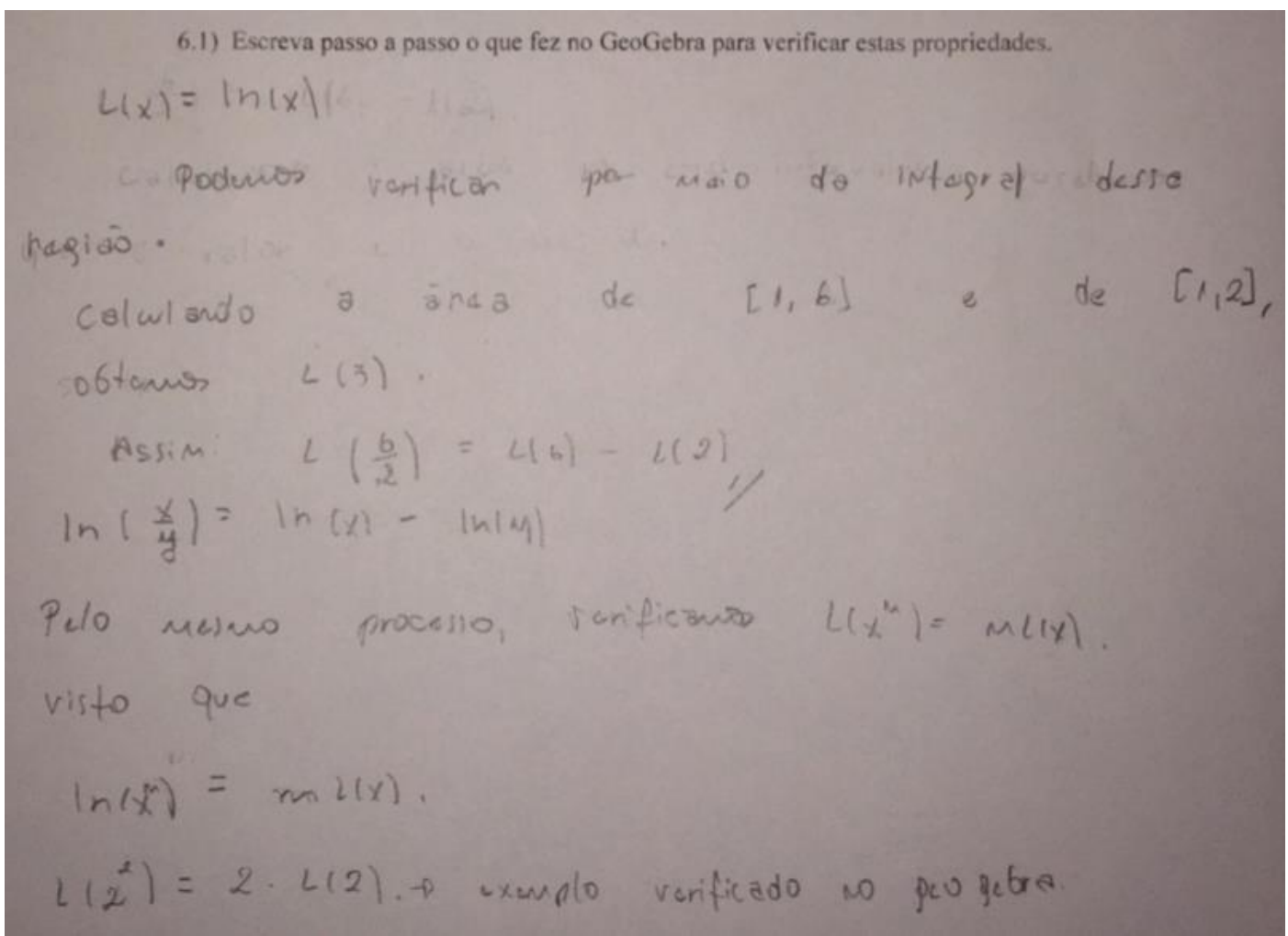

Figura 15 - Registro de A9

Fonte: autores

Foi constatado que desses 9 alunos, 5 conseguiram justificar a propriedade anterior 5.2, no entanto nesta Tarefa 6 , os 9 alunos citados conseguiram avançar e mostrar a propriedade da divisão e da potência para o logaritmo.

Os alunos A3, A5 e A6 apresentaram suas respostas de maneira confusa, impedindonos de efetuar qualquer análise mais detalhada.

Com estas tarefas 5 e 6, realizou-se a verificação das propriedades da redução de algumas operações aritméticas dos logaritmos a operações mais simples.

Por fim, na Tarefa 7, esperava-se que os participantes estabelecessem uma relação entre a função $\mathrm{L}(x)$, a hipérbole $y=1 / x$, e a Função Logarítmica.

\section{TAREFA 7:}

7.1) Com base em todas atividades anteriores, podemos afirmar algo sobre a função $L(x)$ ? Você teria um nome para esta função? Como podemos relacionar esta função com a hipérbole $y=1 / x$ ?

Figura 16 - Tarefa 7

Fonte: autores

Tangram - Revista de Educação Matemática, Dourados - MS - v.2 n. 3, pp. $49-67$ (2019) 


\section{A identificação da Função Logarítmica num trabalho com o software GeoGebra e futuros professores de Matemática}

Como resposta a esta tarefa tivemos que os alunos A1 e A7 não reconheceram a função $\mathrm{L}(x)$, conforme a resposta de A1:

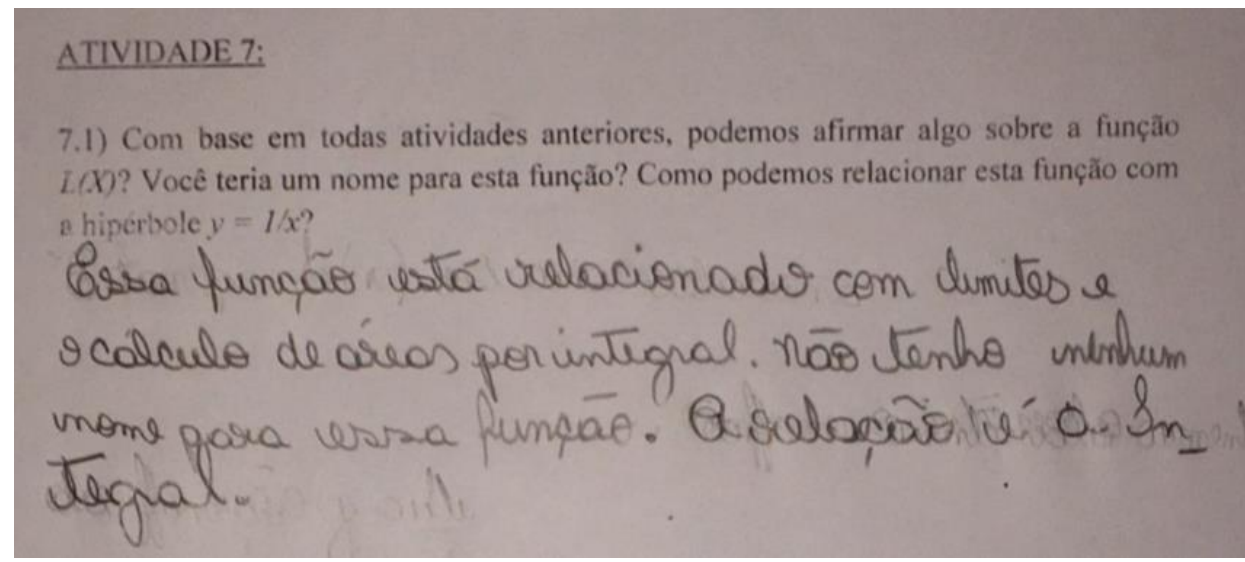

Figura 17 - Registro de A1

Fonte: autores

Não foi possível interpretar a resposta de A3, já os demais alunos concluíram a tarefa com sucesso. Como exemplo, apresentamos a descrição do raciocínio de

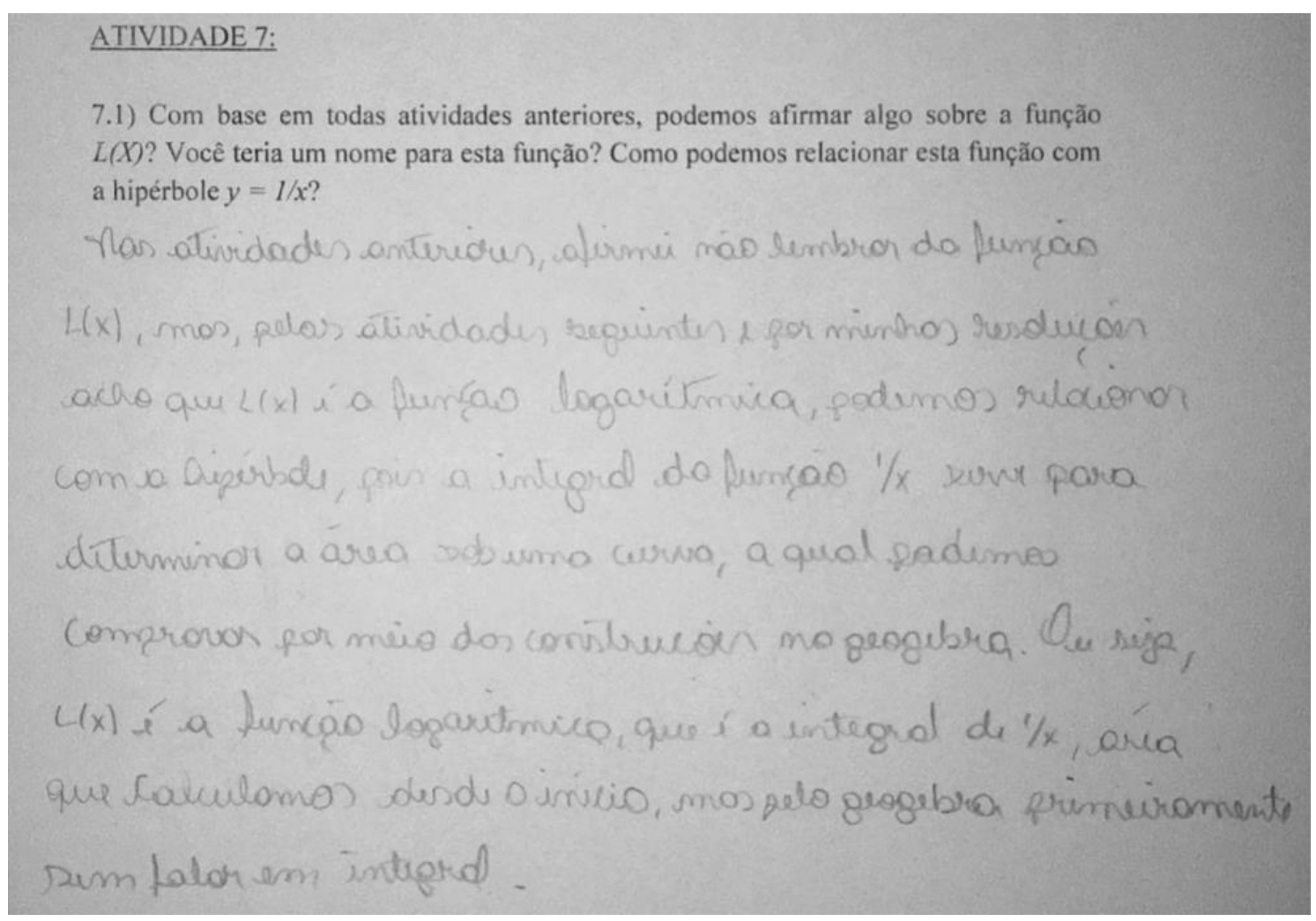

Figura 18 - Registro de A4

Fonte: autores

Tangram - Revista de Educação Matemática, Dourados - MS - v.2 n. 3, pp. $49-67$ (2019) 


\section{A identificação da Função Logarítmica num trabalho com o software GeoGebra e futuros professores de Matemática}

Deste modo, o objetivo da sequência de tarefas foi alcançado já que a maioria ( 9 de 12 alunos) conseguiu reconhecer a função logarítmica e compreender sua interpretação geométrica, bem como a interpretação de suas propriedades. Mesmo com o aparecimento de algumas respostas incompletas e equivocadas durante a aplicação das tarefas, observamos que no seu decorrer, os alunos avançavam e refinavam as suas ideias e consequentemente as suas respostas.

Desta forma, ao submeter alunos do $4^{\circ}$ ano de licenciatura em Matemática a atividades usando o software GeoGebra, 9 de 12 alunos, foram capazes de identificar uma Função Logarítmica quando esta é definida de um modo menos usual, ou seja, definida de modo diferente dos comumente utilizados pelos livros didáticos. A sequência de tarefas proposta aliada ao uso do software proporcionou tal identificação pela maioria dos alunos participantes.

Uma síntese dos resultados podemos visualizar no quadro a seguir:

\begin{tabular}{|c|c|}
\hline \multicolumn{2}{|c|}{ Quadro 2 - Resultados } \\
\hline $\begin{array}{c}\text { Construção da função } \\
\text { (Não realizada ou } \\
\text { inadequada) }\end{array}$ & 0 (nenhum aluno) \\
\hline $\begin{array}{c}\text { Fase 2 } \\
\text { (Incompleta) }\end{array}$ & 0 (nenhum aluno) \\
\hline $\begin{array}{c}\text { Fase 3 } \\
\text { (Adequada) }\end{array}$ & 12 (doze alunos) \\
\hline $\begin{array}{c}\text { Reconhecimento da função } \\
\text { Fase 4 }\end{array}$ & 2 (dois alunos) \\
A1, A7 \\
\hline $\begin{array}{c}\text { (Não realizado ou } \\
\text { inadequado) }\end{array}$ \\
\hline $\begin{array}{c}\text { Fase 5 } \\
\text { (Incompleto) }\end{array}$ & $\begin{array}{c}\text { 1 (um aluno) } \\
\text { A3 (nove alunos) }\end{array}$ \\
\hline $\begin{array}{c}\text { Fase 6 } \\
\text { (Adequado) }\end{array}$ & $\begin{array}{c}\text { A2, A4, A5, A6, A8, A10, A11, A12 } \\
\text { A9, Fonte: autor }\end{array}$ \\
\hline
\end{tabular}

Fonte: autores

Foi perceptível o fato de os alunos participantes não terem tido dificuldades durante a utilização do GeoGebra para a construção e no momento em que se exigiu uma interpretação (reconhecimento da função), apenas 3 alunos apresentaram dificuldades.

Tangram - Revista de Educação Matemática, Dourados - MS - v.2 n. 3, pp. $49-67$ (2019) 
A identificação da Função Logarítmica num trabalho com o software GeoGebra e futuros
professores de Matemática

\section{Considerações finais}

Possibilitar aos alunos um ambiente de experiências matemáticas num desenvolvimento de investigações viabiliza a prática, desenvolve a autonomia e a pesquisa matemática, conforme pudemos comprovar com as atividades realizadas nessa pesquisa. Além disso, quando esse ambiente é a sala de aula de um curso de formação de professores, tal ação se torna ainda mais potencializada, já que esses futuros professores poderão implementar essa prática com seus futuros alunos.

A importância de um futuro professor compreender a concepção geométrica da Função Logarítmica, que conforme Lima (2010, p. 31) é "natural, intuitiva e instrutiva", consiste na necessidade de que o professor deve conhecer além da forma comumente apresentada nos livros didáticos.

Com esta pesquisa, concluímos que a abordagem geométrica para a Função Logarítmica é eficaz no sentido de que proporciona o reconhecimento de suas propriedades e uma nova forma de visualizar essa função. Além dessa proposta diferir da dos livros didáticos, esta pode ser implementada não somente no Ensino Superior, mas também no Ensino Médio.

Outro fator relevante, diz respeito a contribuição do software GeoGebra para a construção da função em questão, pois as mudanças de comportamento do gráfico construído foram agilizadas e proporcionaram um estudo mais aprofundado da função representada figuralmente.

Esperamos que este artigo sirva de referência não só para trabalhos acadêmicos, mas também para as salas de aulas do Ensino Médio e de Formação de Professores, já que no exercício da docência as pesquisas realizadas podem retornar às salas de aula como propostas de ensino e aprendizagem.

\section{Referências}

Almouloud, S. A. (2011) As transformações do saber científico ao saber ensinado: o caso do logaritmo. Educar em Revista. Curitiba-PR/Brasil. n. Especial 1/2011, p. 191-210, Editora UFPR.

Bertini, L. F.; Passos, C. L. B. (2008) O Uso da Investigação Matemática no Processo de Ensino e Aprendizagem nas Séries Inicias do Ensino Fundamental. Encontro Brasileiro de Pós-Graduação em Educação Matemática. Unesp - Rio Claro SP/Brasil.

Tangram - Revista de Educação Matemática, Dourados - MS - v.2 n. 3, pp. $49-67$ (2019) 

A identificação da Função Logarítmica num trabalho com o software GeoGebra e futuros
professores de Matemática

Bicudo, M. A. V. (2004) Pesquisa Qualitativa e Pesquisa Qualitativa Segundo a abordagem fenomenológica. In: BORBA, M. C.; ARAÚJO, J. L. (Orgs). Pesquisa Qualitativa em Educação Matemática. Belo Horizonte-MG/Brasil. Editora Autêntica.

Brousseau, G. (1996) Fundamentos e Métodos da Didáctica da Matemática. In: BRUN, J. Didática das Matemáticas. Tradução de: Maria José Figueiredo. Lisboa: Instituto Piaget, Cap. 1. pp. 35-113.

Dante, L. R. (2005) Matemática: volume único. São Paulo/Brasil. Editora Ática.

Ferreira, L.; Barros, R. M. O. (2010) Uma nova métrica, circunferência quadrada e obstáculos. In.: V Congresso Internacional de Ensino da Matemática de outubro de ULBRA. Canoas -RS/Brasil.

Fiorentini, D.; Lorenzato, S. (2006) Investigação em educação matemática: percursos teóricos e metodológicos. Campinas-SP/Brasil: Autores Associados.

Frota, M. C. R. (2007) Experiência matemática na sala de aula da Educação Superior. Anais do IX Encontro Nacional de Educação Matemática. Sociedade Brasileira de Educação Matemática, 2007. Disponível em <www.sbembrasil.org.br/files/ix_enem/Mesa/Artigo_MClaraFrota_MR 13.doc>. Acesso em 09 de março de 2018.

Lima, E. L. (2010) Logaritmos. Rio de Janeiro/Brasil. Editora SBM.

Paraná, S. E. E. (2008) Diretrizes Curriculares da Educação Básica-Matemática.

Paraná, (2019) Programa Educação Conectada. Disponível em:

http://www.gestaoescolar.diaadia.pr.gov.br/modules/conteudo/conteudo.php?conteudo=18 74. Acesso em 07 de agosto de 2019.

Ponte, J. P.; Brocardo, J.; Oliveira, H. (2006) Investigações matemáticas na sala de aula. 1a ed. - Belo Horizonte - MG/Brasil. Editora Autêntica.

Enviado:22/08/2019

Aceito:30/09/2019

Tangram - Revista de Educação Matemática, Dourados - MS - v.2 n. 3, pp. $49-67$ (2019) 